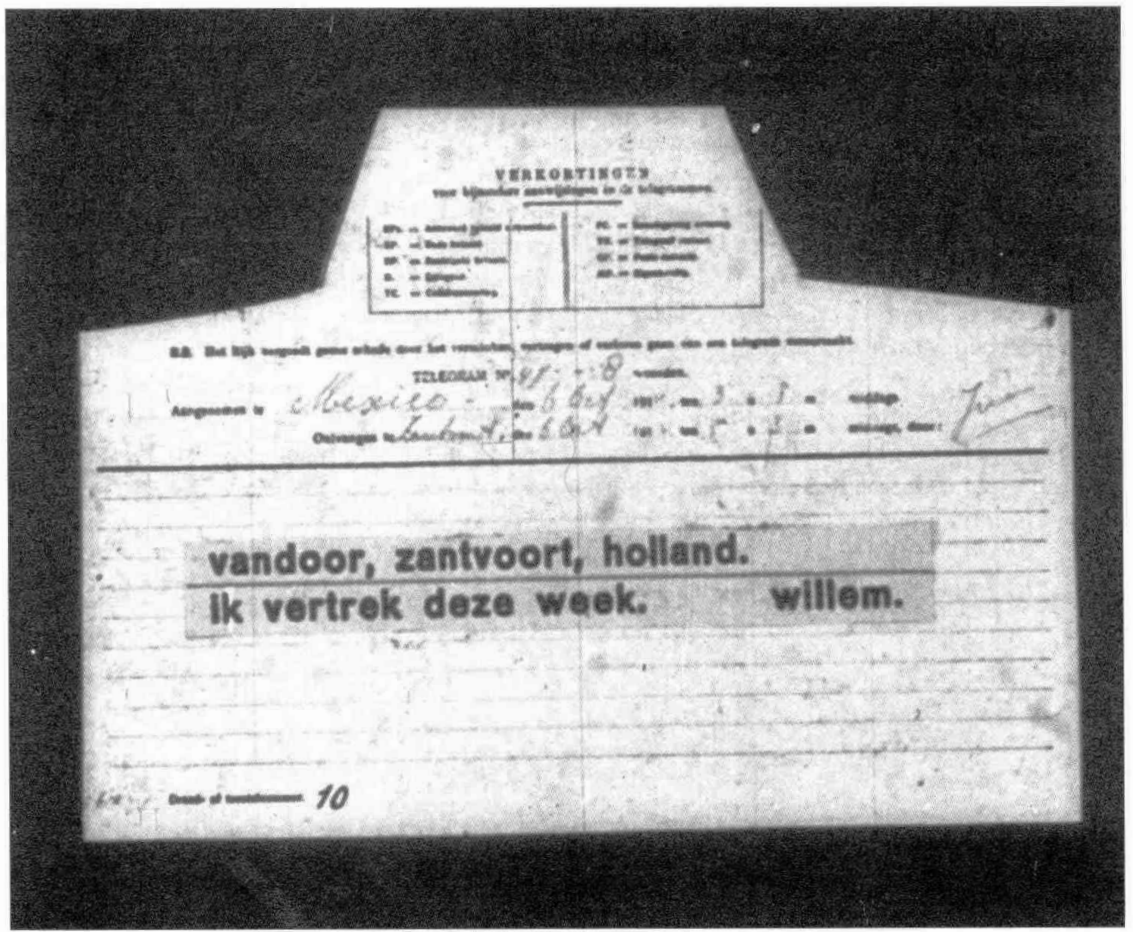




\title{
Redes empresariales en la región de Guadalajara durante el porfiriato
}

\author{
Gladys Lizama Silva* \\ Sergio Valerio Ulloa**
}

\section{LA RED Y SU ESTRUCTURA}

$\mathrm{S}$ i pensamos en el concepto de red, tendremos que referirnos a la estructura de un tejido, cuya textura está conformada por hilos y nudos. El nudo sería la forma básica de la estructura, el punto de confluencia entre dos o más hilos, cuya prolongación hacia distintas direcciones conecta y forma parte de otros nudos, lo cual en conjunto forma una unidad que es la red. Los hilos en esta metáfora serían los vínculos o conexiones entre nudo y nudo.

* Licenciada en Historia por la Universidad de Chile, maestra en Ciencias Sociales, en Estudios Latinoamericanos, por la Facultad Latinoamericana de Ciencias Sociales (FLACSO), sede México, y doctora en Ciencias Sociales en Historia por CIESAS-Occidente. Trabajó varios años como investigadora en El Colegio de Michoacán. Actualmente se desempeña en el Centro Universitario de Ciencias Sociales y Humanidades de la Universidad de Guadalajara. Es autora del libro Zamora en el porfiriato. Familias, fortunas y economia, editado por el Colmich en el año 2000 y ha coordinado los libros Modernidad y modernización en América latina. México y Cbile, siglos XVIII al $\mathrm{XX}$, publicado en México y en Chile en 2001 y 2002, y México y Cuba, siglos de bistoria compartida, de reciente aparición bajo el sello editorial de la Universidad de Guadalajara.

** Doctor en Historia por El Colegio de México. Profesor-investigador del Departamento de Historia de la Universidad de Guadalajara. Coordinador de la
La sociología y la antropología han sido generosas en proporcionar definiciones de lo que es una red, sin embargo, parece importante recordar, para los fines de este trabajo, la propuesta de Michel Bertrand, historiador francés que ha trabajado por largo tiempo la formación de redes sociales en Nueva España. Él dice:

que la noción red comprende una doble acepción. La red remite en primer lugar a una estructura construida por la existencia de lazos o de relaciones entre diversos individuos [...] [En segundo lugar] la red sería también un sistema de intercambios en el seno del cual los individuos o las relaciones permiten la realización de la circulación de bienes o de servicios. Son estos intercambios realizados dentro de una red lo que se puede calificar de vínculos. ${ }^{1}$

maestría en Historia de México de la Universidad de Guadalajara. Investigador nacional nivel 1. Entre sus publicaciones destacan: Empresarios extranjeros en Guadalajara durante el porfiriato, Universidad de Guadalajara, 2002; Historia rural Jalisciense. Economía agrícola e innovación tecnológica durante el siglo XIX, Universidad de Guadalajara, 2003. Ha publicado diversos artículos en revistas nacionales y en libros colectivos sobre historia económica regional y sobre empresas y empresarios en Jalisco durante el siglo XIX.

' Bertrand, "Familia", 1999, p. 119 
Sostiene también que en la red hay una transversalidad de los vínculos. Esto significa que los intercambios afectan y atraviesan toda la red,

en este sentido, la red consiste en un complejo sistema de vínculos que permiten la circulación de bienes y servicios, materiales e inmateriales, en el marco de las relaciones establecidas entre sus miembros. ${ }^{2}$

El concepto red trasladado al análisis de las relaciones de los empresarios y sus empresas sólo puede ser utilizado de forma metafórica, pues la estructura de la red puede ser muy simple y horizontal, lo cual no explica la complejidad de relaciones que puede tener un grupo de empresarios o un conjunto de empresas. Sin embargo, para fines de la explicación, podemos aceptar que la estructura de red puede ser un símil muy limitado para explicar la estructura de las relaciones entre empresas y empresarios.

A menudo se asocia el concepto de empresa con un local, un establecimiento o edificio determinado, por ejemplo, una fábrica, una mina, oficinas de un negocio, un almacén o una tienda, pero de acuerdo con la definición que dan distintos teóricos de la economía, una empresa, aunque se asocia a estos lugares y edificios, no es precisamente el lugar edificado, sino la organización de los distintos factores productivos, sociales e informáticos para conseguir un fin económico, lo cual está asociado o deriva en otros fines sociales, políticos y culturales para la empresa y para sus propietarios, los empresarios.

La empresa tiene estructuras jurídica, económica y social que la definen como una unidad en cuanto a la propiedad, el

${ }^{2} I$ bid., p. 120. sistema económico y las relaciones sociales que se tejen hacia adentro y hacia fuera de la empresa, por ello los límites de la empresa no son sólo las bardas que circundan las fábricas, las casas o los terrenos de los edificios, sino la propiedad en el marco jurídico respecto a otros propietarios, el mercado y otras empresas económicas y los derechos de los distintos individuos y grupos que tienen interacción dentro y fuera de la empresa.

Así, pues, una empresa no está aislada, sino que está inmersa en un sistema de relaciones jurídicas, económicas y sociales que determinan sus actividades y su funcionamiento. Este sistema es lo que últimamente los economistas han llamado red. Las relaciones son vínculos o conexiones, lo que es la base de un tejido económico o social, que sin dejar el símil textil, las empresas y los empresarios tejen como un medio para alcanzar sus fines económicos, como la ganancia y el lucro, o sociales, como el reconocimiento y el prestigio, o políticos, como el poder.

Ahora bien, hay de redes a redes, según los fines y los propósitos. Desde luego, una red para pescar atunes no sirve para pescar camarones, el objetivo define el tipo de red que se va a tejer y que se va a utilizar para lograr el fin propuesto. ${ }^{3}$ Estos conceptos de red o redes bien podemos apli-

3 "El análisis de redes sociales estudia relaciones específicas entre una serie definida de elementos (personas, grupos, organizaciones, e incluso elementos del discurso). Cada tipo de relación implica una red diferente (la red de amistad no puede ser igual que la de enemistad), aunque algunas de ellas pueden ser muy similares". José Luis Molina y Claudia y Aguilar, "Redes sociales y antropología: un estudio de caso (discursos étnicos y redes personales entre jóvenes de Sarajevo)" en <http://seneca.uab.es/antropologia/jlm/ public_archivos/Redyant.pdf $>$. 
carlos al sistema de vínculos y conexiones que tenían las empresas y los empresarios del siglo $\mathrm{xIX}$, de acuerdo con sus fines $\mathrm{y}$ con las condiciones sociales, económicas y políticas en las que se hallaban inmersos.

Lo esencial de la red son los hilos y los nudos que, conectados entre sí, conforman un tejido. Si aceptamos la analogía, entonces podemos decir que un empresario, una familia de empresarios, o una empresa, ya sea individual, familiar, en comandita o por acciones, pueden tomar el lugar de los nudos de la red, y el lugar de los hilos lo tomarán todas aquellas relaciones que establecen o que tejen los empresarios o las empresas con otros empresarios, empresas o actores económicos, sociales o políticos, o en general con su entorno, en sentido vertical $\mathrm{u}$ horizontal, si hablamos de jerarquías, o a nivel local, regional, nacional e internacional, si hablamos de mercados o espacios geopolíticos.

\section{EL EMPRESARIO INDIVIDUAL, EL NUDO MÁS FINO}

No es extraño que un individuo en concreto, ya sea comerciante, terrateniente, industrial o banquero, sea tomado como el centro de múltiples relaciones o vínculos, pues presuponemos que éste forma parte de una sociedad en donde los miembros que la componen están interrelacionados o establecen múltiples interdependencias entre sí. Decir que un individuo es el "centro" de múltiples vínculos es simplemente cuestión de método para el análisis de las relaciones sociales, cambiando el enfoque del grupo o de la comunidad al del individuo en sus relaciones e interdependencias con otros individuos. Los "centros" serían en la metáfora de la red los nudos con todo y sus vínculos, porque, otra vez volviendo al uso y manejo del lenguaje y de los conceptos, no hay centro sin su periferia ni nudo sin sus hilos.

Si tomamos a los socios de la Cámara Agrícola Jalisciense o de la Cámara de Comercio de Guadalajara de finales del porfiriato, encontraremos estructuras comunes a todos ellos, cosas obvias si se piensa así; todos son parte de una familia tanto nuclear como ampliada, en donde hay relaciones de parentesco consanguíneo y parentesco político, con todo lo que ello significa social y culturalmente para la época y la sociedad del occidente de México del siglo XIX y principios del XX. Como propietarios rústicos y urbanos, dueños de haciendas, ranchos, terrenos y casas en las ciudades más grandes de la región, así como comerciantes, industriales y banqueros dueños de capitales, fábricas, almacenes comerciales y bancos, inmersos en un sistema económico y jurídico predominantemente capitalista, tienen y establecen relaciones económicas y vínculos entre ellos mismos dentro de la región o con otros grupos de individuos, ya sean empresarios, clientes, trabajadores, consumidores, deudores y acreedores dentro y fuera de la región, llegando a distintas regiones del país y del extranjero.

Como miembros de las familias más poderosas de la región en términos políticos, económicos y sociales, dichos individuos conformaban una elite en la cual los lazos de matrimonio, parentesco, amistad, compadrazgo y las relaciones económicas eran los vínculos que estrechaban y cohesionaban a los miembros de dicha elite. Esto no lo podemos explicar a detalle si no exponemos el caso de alguno o algunos de los individuos concretos a los que estamos aludiendo. 
En las páginas siguientes explicaremos cómo se estructuraban estas redes empresariales en la región de Guadalajara durante el porfiriato. Para ello dividimos el trabajo en varios apartados: la red primaria de parentesco de tres empresarios; los vínculos creados por estos tres grandes empresarios; algunos ejemplos de compañías mercantiles; sociedades por acciones y asociaciones de compañías, y finalmente las conclusiones.

\section{LAS REDES DE PARENTESCO: NICOLÁS Remus, TeOdoro KunHardT, Francisco Martínez Negrete}

Es importante hacer una revisión de las redes de parentesco porque desempeñaron un papel en la formación de redes mercantiles, de negocios y empresariales. En algunos casos es claro que unas derivan en las otras.

Nicolás Remus vino al mundo como hijo de una familia de la elite regional. Su padre fue José Remus Baz, un catalán que llegó a residir a Hostotipaquillo, municipio de Jalisco, en donde se casó con Aleja Vallarta. José Remus fue dueño de la hacienda de Arroyo Hondo, situada en Hostotipaquillo, y un activo comerciante en esta región durante la primera mitad del siglo XIX.

Por su parte, Aleja Vallarta fue hija de Norberto Vallarta, un importante comerciante de la región; sus hermanos fueron Apolonia e Ignacio. Este último fue padre del connotado político liberal jalisciense Ignacio L. Vallarta, de tal manera que Nicolás Remus fue primo hermano de Ignacio $L$. Vallarta. Así que, por el lado materno, sus vínculos familiares no sólo lo relacionaron con la elite terrateniente, pues
Apolonia fue dueña de la hacienda de El Cuatro, cercana a Guadalajara, sino con la elite política, de tal manera que lo llevaron a ocupar una regiduría en los cabildos de Guadalajara de 1839,1856 y $1857,{ }^{4}$ además de una diputación local durante el periodo de 1867-1870, y fue designado por su primo Ignacio L. Vallarta como director de Rentas del gobierno del estado de Jalisco en $1871 .^{5}$

El núcleo de los vínculos de Nicolás Remus lo constituían sus lazos familiares, y éstos se ampliaron cuando se casó, a mediados de los años treinta del siglo XIX, con Mercedes Luna. Ésta fue hija de otro comerciante importante de la región, Manuel Luna, de origen español, y de Antonia Rivero. Nicolás y Mercedes tuvieron diez hijos de los cuales sobrevivieron ocho: Isabel, Refugio, Jesús, Mercedes (mujeres), y José, Ignacio, Miguel y Ramón (varones). Cuando Nicolás se casó introdujo a la sociedad conyugal un capital de 14000 pesos, mientras que Mercedes introdujo al matrimonio la cantidad de 10934 pesos. Hacia 1851 , Nicolás y su suegro compraron por partes iguales la hacienda de El Plan, por la cantidad de 80000 pesos.

Por su parte, Teodoro Kunhardt nació el 20 de noviembre de 1816 en Lübeck, Alemania, hijo de Enrique Kunhardt y Dorotea Richertz. Teodoro tuvo una prole muy numerosa; sus hijos fueron Federico, Othón, Guillermo y Germán; y sus hijas fueron Marina, Gertrudis, Laura, Dorotea, Adela y Otilia. A través del matrimonio de sus hijas, Teodoro Kunhardt reforzó los vínculos con algunos de sus socios, como fueron los casos de Enrique Blume, casado con Marina; Gustavo

${ }^{4}$ López, Guadalajara, 1987, pp. 281, 318 y 320.

${ }^{5}$ Pérez, Historia, 1989, t. III, p. 388. 
Scheiber, casado con Gertrudis; Andrés Morfín, casado con Laura; y Julio Rose casado con Dorotea.

No fue muy diferente el caso de Francisco Martínez Negrete Ortiz de Rosas, inmigrante vasco que llegó a Guadalajara aproximadamente en la segunda década del siglo XIX. Después de enviudar de su primera esposa, María Trinidad Roncal, se casó en segundas nupcias con su sobrina en segundo grado, situación que permite inferir que hubo parientes que pudieron servir de apoyo en los inicios de su carrera como comerciante. Una de las hermanas de su segunda esposa, Antonia Alba Ortiz de Rosas, fue la primera esposa de Francisco María Ortiz, ${ }^{6}$ otro comerciante y hacendado vasco, nacido también en Lanestosa, que sin ser de las más grandes fortunas, sí tuvo bastante influencia económica en Guadalajara; éste, a su vez era compadre de Simón F. Del Llano, socio de Francisco Martínez Negrete en la explotación de la hacienda de Cuisillos, propiedad de ambos por varios años. ${ }^{7}$ Sus hijas se unieron en matrimonio con individuos de origen español que fueron comerciantes y empresarios de gran peso económico en la región y, además, uno de ellos lo fue en la ciudad de México. ${ }^{8}$ Rosalía y María Josefa se casaron con los hermanos Manuel y Justo Fernáñez del Valle y Álvarez de la Vallina, respectivamente; Agapito Fernández Somellera se casó pri-

${ }^{6}$ Este personaje aparece mencionado en varias ocasiones en Olveda, Oligarquía, 1991, pp. 265 y 392.

${ }^{7}$ Archivo Histórico y de Instrumentos Públicos de Jalisco (en adelante AHIPJ), Testamento de Francisco María Ortiz, Juan Riestra, 17 de septiembre de 1870, fs. $199 \mathrm{v}-202 \mathrm{v}$.

${ }^{8}$ Valerio, "Capitalismo", 1999, pp. 593-595, y Olveda, Oligarquia, 1991, caps. 5 y 6 . mero con Lorenza Martínez Negrete Alba. Cuando ésta falleció contrajo segundas nupcias con su hermana Francisca. María Ignacia y María Dolores se ligaron a través del matrimonio con Pío y José María Bermejillo e Ibarra, respectivamente. ${ }^{9}$ En este caso, la red familiar creada prestó bienes y servicios a los yernos que se beneficiaron de su asociación con el padre político, y éste del trabajo y el capital que aquéllos aportaron a las sociedades mercantiles familiares creadas por Francisco Martínez Negrete. En la etapa siguiente, el porfiriato, todos ellos se transformaron en poderosos e influyentes comerciantes y empresarios de Guadalajara con negocios y operaciones económicas en un espacio regional que se extendía a todo el occidente de México. ${ }^{10}$

La red de parentesco de la cual Francisco Martínez Negrete Alba formaba parte también fue de importancia extrema, pues las diversas actividades y operaciones económicas que emprendió en los primeros años las realizó en asociación con sus cuñados, los Fernández del Valle, y luego que se separó de ellos, con sus hijos. Avanzada la época porfiriana, como observaremos más adelante, en que entra como accionista de empresas más grandes, siempre

"AHIPJ, Testamentos de Francisco Martínez Negrete, Juan Riestra, 19 de enero de 1861 , fs. $56 \mathrm{v}-59$, y 17 de febrero de 1869. Testamento de Ignacio Célis, 23 de mayo de 1874 , el legajo está compuesto de 57 fojas que en su mayor parte no están numeradas.

${ }^{10}$ José María Bermejillo, padre de Pío y José María, era uno de los comerciantes y capitalistas españoles más prósperos de ciudad de México en la primera mitad del siglo XIX. En el porfiriato Pío Bermejillo fue uno de los accionistas en la creación del Banco Nacional Mexicano, más tarde del Banco Mercantil Mexicano y en 1884 del Banco Nacional de México. Ludlow, "Formación", 1998, pp. 146-161. 
estuvo presente el lazo de parentesco porque muchas en las cuales participó, también invariablemente lo hicieron los Fernández del Valle y otro de sus cuñados, Agapito Fernández Somellera. La gran diferencia con su padre es que no se perciben en él estrategias matrimoniales étnicas y económicas convenientes para la buena marcha de los negocios, sin que eso signifique que sus hijos se hayan casado mal o no se evidencie endogamia, pues su hijo homónimo se emparentó con los Palomar y Corcuera, dos apellidos de familias de reconocida trayectoria social y económica en Guadalajara; pero con los demás hijos no sucedió lo mismo, éstos se emparentaron con los Villaseñor, los Parra Romero y los López, apellidos que no estuvieron entre la elite económica y social de mayor resonancia.

La descendencia masculina de la familia Martínez Negrete con influencia económica en Guadalajara y su región terminó cuando Francisco, uno de los dos hijos hombres, quebró estrepitosamente en. 1901. ${ }^{11}$

LAS REDES EMPRESARIALES Y DE NEGOCIOS

\section{Nicolás Remus ${ }^{12}$}

En los inicios del porfiriato, Nicolás Remus era dueño de tres haciendas: El Plan, Bellavista y Navajas, en los municipios de Acatlán y Tala, en el estado de Jalisco. Dentro de la hacienda de Bellavista había

${ }^{11}$ El hijo del primer matrimonio, José María Martínez Negrete Roncal, centró sus negocios en Michoacán. 494. establecido un ingenio azucarero con la maquinaria y los métodos más modernos de la época. Además tenía una tienda en Guadalajara y era dueño de varias casas en esa ciudad y en la villa cercana de San Pedro Tlaquepaque. ${ }^{13}$

Como propietario agrícola era cabeza de una gran comunidad, pues hacia 1886 las tres haciendas mencionadas fueron registradas como una sola propiedad, con una extensión aproximada de 19316 hectáreas y con un valor de 650000 pesos. Sin embargo, no sólo fue el centro de múltiples relaciones con sus empleados y trabajadores en dichas haciendas, sino que paralelamente a su actividad como hacendado, desempeñó una intensa actividad como empresario comerciante, industrial $y$ financiero.

Nicolás Remus, junto con otros empresarios capitalistas, impulsó la creación del Banco de Jalisco en 1882, proyecto que no llegó a concretar debido a la prohibición que estableció el gobierno federal en esos años para establecer bancos regionales. Por esto no le quedó otra alternativa que participar como socio en la Sucursal del Banco Nacional de México que se estableció en Guadalajara en 1884. En estos dos proyectos Nicolás Remus se relacionó como socio con empresarios capitalistas de Guadalajara y de la ciudad de México, como Manuel L. Corcuera, los hermanos Fernández del Valle, los Fernández SomeHera, los Palomar, Diego Moreno, Francisco Martínez Negrete, Antonio Álvarez del Castillo, Luciano Gómez; Cástulo

${ }^{13}$ Toda la información que se ha encontrado sobre Nicolás Remus proviene de AHJPJ de los protocolos de Francisco González Palomar, tt. 4 y 13 (1886-1887), y de Heraclio Garciadiego, tt. 12, 24, 28, 38, 39, 47 (1879-1889). 
Martínez Gallardo, José María Veréa y Feliciano Orendáin, así como con José María Bermejillo como representante del Banco Nacional de México.

Si todavía queda duda de que Nicolás Remus era un abigarrado nudo de relaciones sociales y económicas, podemos agregar que fue un prestamista muy solicitado en una época en donde los bancos apenas iniciaban sus actividades financieras. Al momento de su muerte, en 1886, sus inventarios registran una extensa lista de deudores que lo mismo incluía a su familiares y parientes más cercanos, como a clientes, comerciantes y compañías situadas de distintas partes del interior del estado de Jalisco y de diversas ciudades del país como Aguascalientes, Tepic, Guaymas, Mazatlán, ciudad de México, Guanajuato y Zacatecas. Si partiéramos de Nicolás Remus siguiendo a cada uno de los empresarios con que tuvo contacto, relaciones o vínculos, podríamos construir una extensa red, pero la metáfora no se adecua al formato del texto ni a su espacio, así que contentémonos por ahora con la lista de deudores que muestra el cuadro 1 .

De la misma forma en que Nicolás Remus prestaba dinero o daba crédito, otras personas y compañías le otorgaban crédito a él, y aunque el importe de sus deudas no era muy grande, según sus inventarios, pues apenas representaba $2.74 \%$ de su fortuna, este tipo de relaciones muestra la red financiera que tejía Nicolás en torno a su persona y sus empresas. $\mathrm{Ni}$ colás Remus debía pequeñas cantidades a sus proveedores, entre los cuales se encuentran: Federico Probst y Cía,, Castillo y Zúñiga, F. De la Peña y Hermano, Palomar Hermanos, Manuel L. Corcuera e Hijos, José Garibi, Compañía de Ingenieros
Constructores y la Julio Jürgensen y Cía., entre otros. ${ }^{14}$

\section{Teodoro Kunbardt ${ }^{15}$}

Si queremos ver un modelo distinto de la red que forma un empresario para hacer sus negocios, tenemos que tomar el caso de un empresario alemán radicado en Guadalajara durante la segunda mitad del siglo XIX. Siendo muy joven fue enviado por su padre al norte de Alemania con el objetivo de que se dedicara a actividades relacionadas con el comercio de granos, pero a los pocos meses resolvió enviarlo para América, por lo que se dedicó al comercio de importaciones y exportaciones. Así fue como el 4 de octubre de 1833, a los 16 años de edad, se embarcó en Hamburgo con destino al puerto de Valparaíso, Chile.

Kunhardt llegó a Valparaíso hasta el 16 de enero de 1834 , después de tres meses de travesía. En este puerto lo recibió su hermano Jorge Enrique, quien era socio y administrador de la casa Kunhardt Kaiser et Hayn. Ahí permaneció como empleado hasta que en septiembre de ese mismo año fue enviado por sus jefes a Nicaragua, donde permaneció un año. Posteriormente, por instrucciones de la misma casa comercial, se trasladó al puerto de Guaymas, Sonora, en territorio mexicano. Llegó a éste el 30 de septiembre de

${ }^{14}$ AHIPJ, Francisco González Palomar, Libro de Documentos, t. 13, 1886-1887.

15 Sobre Teodoro Kunhardt, véanse Santoscoy, Obras, 1986, t. II, pp. 11-114; Olveda, Oligarquía, 1991, pp. 381-384; Martínez, Tapatíos, 1987, pp. 198-199, y Valerio, "Teodoro", 2000, pp. 77-96. 


\section{SECUENCIA}

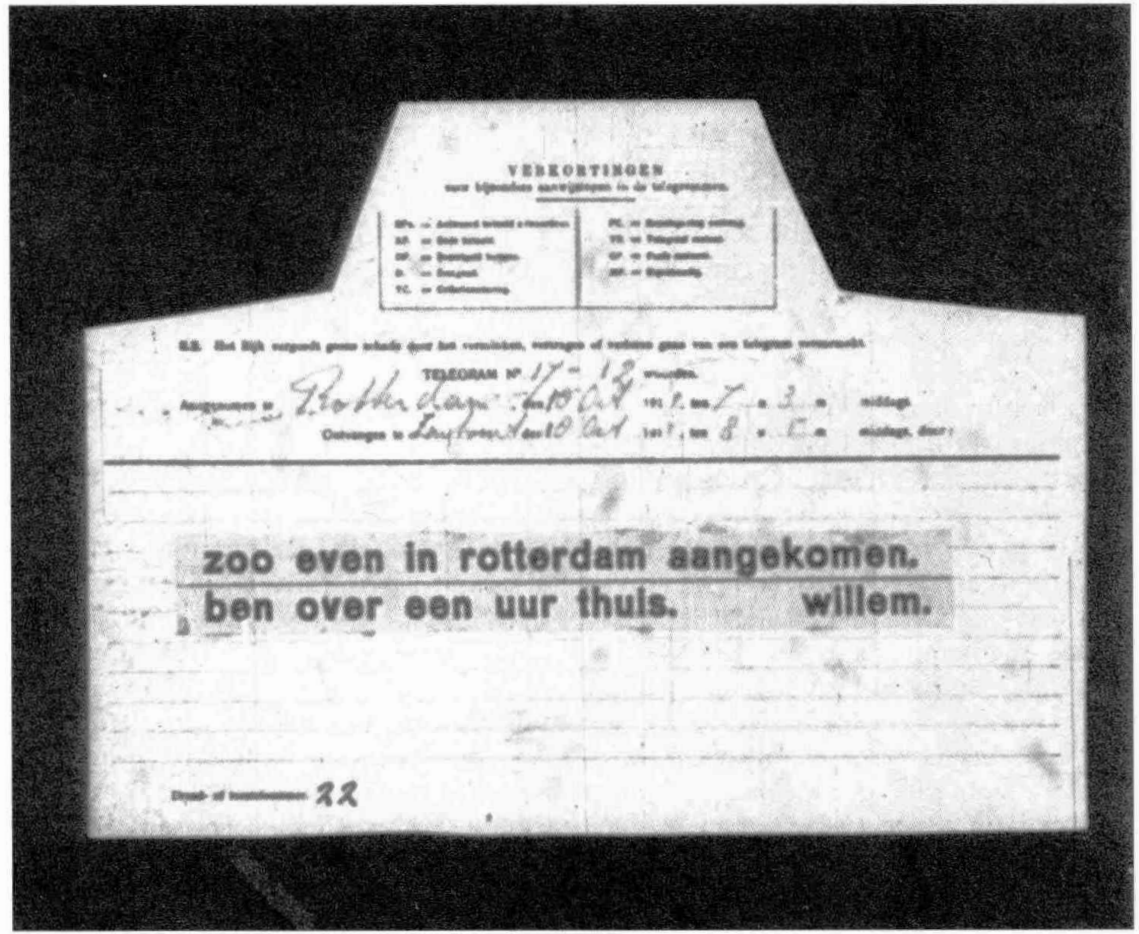


Cuadro 1. Lista de deudores de Nicolás Remus (1886)

Deudor

Carlos Duque

Apolonia Vallarta

Refugio Guischard

Jesús Negrete

Gabriel Castaños

Tomás D. Veitia

Fernando Araiza

Ignacio Aguilar

G. Moller y Cía.

Miguel Remus

Ignacio Baeza

Jósé Fernández

Somellera y Cía

José García

Juan Corona

Gabriel Castaños

Ladislao Gómez

Severo Vizcaíno

Bermejillo y Cía.

José María Topete y Cía.

Ramón Remus

Isabel Remus de Duque

F. A. Aguilar Sucs.

Miguel Gómez

Jesús Camarena

Carlos F. de Landero

Osunte Hermanos

Ildefonso Baeza

Luis Macías

Ignacio Remus

Carmen Rosales

José Remus

Cuentas de cambio
Lugar de residencia

Guadalajara

Hacienda de Santa Cruz

Aguascalientes

Tepic

Guadalajara

Guadalajara

Autlán

Guadalajara

Guaymas

Guadalajara

Santa Ana

Guadalajara

Mazatlán

Guadalajara

Aurlán

Guadalajara

Santa Ana

Zapotlán

Ciudad de México

Autlán

Guadalajara

Hacienda de Bellavista

Guaymas

Hacienda de Santa Cruz

Guadalajara

Guadalajara

Guanajuato

Santa Ana

Zacatecas

Guadalajara

Guadalajara

Guadalajara

Ciudad de México
Cantidad (pesos)

43403

118822

2210

633

31145

180

1867

3675

9150

21376

488

1621

9396

6630

230

24906

12373

35215

3799

2610

22607

705852

1649

61265

3604

6327

1743

6321

13572

49663

2060

29549

65

Fuente: AHIPJ, Francisco González Palomar, Libro de Documentos, t. 13, 1886-1887. 
1835 , en donde la casa comercial tenía otra sucursal. A principios de 1840 , se trasladó al puerto de Mazatlán con el fin de hacerse cargo de la sucursal que la Kunhardt Kaiser et Hayn había fundado años atrás en dicho puerto. Trabajó para esta casa comercial hasta fines de 1843 y a partir del 1 de enero de 1884 , a los 27 años, estableció su propia empresa en Mazatlán junto con Eduardo Ewald bajo la razón social de Kunhardt et Ewald.

Este mismo año fue nombrado cónsul de Prusia en Mazatlán, por el rey Federico Guillermo IV. Durante su estancia en este puerto contrajo matrimonio con Marina Urrea, originaria de Mazatlán. Posteriormente, en 1852, se trasladó a Guadalajara, donde fundó una casa comercial con el mismo nombre que la que estaba en Mazatlán. Su actividad comercial, industrial y financiera fue muy intensa en esta ciudad. En 1855 se asoció con Julio Enrique Blume, de nacionalidad alemana, y con Manuel L. Corcuera. Dicha casa comercial tuvo sucursales en Colima y Tepic, por lo que surtiría mercancías a los comerciantes del Bajío, Colima, Tepic, Aguascalientes, Guanajuato y Michoacán. Tan importante era su actividad comercial que en 1855 fue nombrado nuevamente cónsul de Prusia, pero ahora en la ciudad de Guadalajara, y por su actividad consular fue condecorado el I de mayo de 1867, con la Cruz del Águila Roja por parte del rey Guillermo ${ }^{16}$ (véase cuadro 2).

Al mismo tiempo que participaba en estos negocios, Teodoro Kunhardt era propietario de dos haciendas en el territorio de Tepic, denominadas Chila y Las Varas, que tenían un valor total de 14000 pesos. Además de ser un activo financiero y pres-

$$
{ }^{16} \text { Valerio, "Teodoro", 2000, p. } 33 .
$$

tamista que favorecía a otros empresarios comerciales e industriales de la región, también fue propietario de varias fincas urbanas en Guadalajara, San Pedro Tlaquepaque y Compostela.

Kunhardt murió el 27 de octubre de 1892 , el valor de sus inventarios en esa fecha sumaron la cantidad de 367812 pesos. Entre sus activos, junto a sus propiedades rústicas y urbanas, se encontraban 20 bonos en la Cía. Anónima del Monte de Piedad y Caja de Ahorros de Guadalajara por 20000 pesos; acciones en la Cía. de Tranvías del Santuario a Mexicaltzingo, por 29 112; cinco bonos en la Cía. del Ferrocarril de Guadalajara a San Pedro, por 26100 pesos; acciones en la "Cía. Kunhardt y Rose", por 59 500. También se encontraban registrados los siguientes créditos a cargo de distintas personas y compañías: ${ }^{17}$

Nombres

Monto en pesos

The London San Francisco

Bank Limited, de San

Francisco, California, en los Estados Unidos de Norteamérica 10000

F. A. Aguilar y Sucesores, de la ciudad de Guaymas, Sonora

Banco Nacional del Paso,

Texas, en los Estados Unidos

de Norreamérica

1000

Behn y Cía. $\quad 6163$

Kunhardt Rose y Cía. $\quad 1337$

Lino Martínez $\quad 4010$

Bartuing y Sucesores, en Mazatlán

1364

${ }^{17}$ AHIPJ, Salvador España, Libro de Incumentos, 1892-1893. 
Cuadro 2. Empresas en las que participó Teodoro Kunhardt (1834-1892)

\begin{tabular}{|c|c|c|c|}
\hline Nombre de la negociación & Lugar & Años & Capital (en pesos) y socios \\
\hline Kunhardt Kaiser et Hayn & Valparaíso, Chile & $1834-1840$ & $\begin{array}{l}\text { Fue dependiente y agente } \\
\text { comercial. }\end{array}$ \\
\hline Kunhardt et Ewald & Mazatlán & $1844-1852$ & Fue socio capitalista. \\
\hline Blume Kunhardt y Cía. & Guadalajara & 1855 & $\begin{array}{l}\text { Fue socio capitalista, se asoció } \\
\text { con Enrique Blume y con } \\
\text { Manuel L. Corcuera. } \\
\text { Tuvo sucursales en Colima } \\
\text { y en Tepic. }\end{array}$ \\
\hline Ferretería y Mercería & Guadalajara & & $\begin{array}{l}\text { Fue socio capitalista y se asoció } \\
\text { con Federico Cramer }\end{array}$ \\
\hline Kunhardt Esqueda y Cía. & León, Guanajuato & 1863 & Fue socio capitalista \\
\hline Sociedad con Carlos Marcker & Guadalajara & 1866 & $\begin{array}{l}\text { Invirtió } 50000 \text {, fue socio } \\
\text { capitalista, se asoció con } \\
\text { Carlos Marcker. }\end{array}$ \\
\hline $\begin{array}{l}\text { Fábrica textil de Santiago } \\
\text { Ixcuintla }\end{array}$ & Jalisco & 1868 & Accionista y directivo. \\
\hline Eraclio Farías y Cía. & Guadalajara & & $\begin{array}{l}\text { Capital social: } 20000 . \\
\text { Fue socio capitalista, se asoció } \\
\text { con Eraclio Farías. }\end{array}$ \\
\hline Tienda de Abarrotes & Guadalajara & 1880 & $\begin{array}{l}\text { Invirtió } 8000 . \text { Fue socio } \\
\text { capitalista; se asoció con } \\
\text { Juan N. Verea. }\end{array}$ \\
\hline $\begin{array}{l}\text { Cía. de Tranvías } \\
\text { Guadalajara-San Pedro }\end{array}$ & Guadalajara & 1880 & $\begin{array}{l}\text { Invirtió } 5 \text { 000; fue socio } \\
\text { accionista. }\end{array}$ \\
\hline Julio Rose y Cía. & Guadalajara & 1881 & $\begin{array}{l}\text { Capital social: } 60854 \text {. } \\
\text { Fue socio capitalista; se asoció } \\
\text { con Enrique Kuhardt, Julio } \\
\text { Rose y Edmundo Cuevà. }\end{array}$ \\
\hline Cervecería El León & Guadalajara & 1882 & $\begin{array}{l}\text { Capital social } 7363 \text {. Fue socio } \\
\text { capitalista; se asoció con } \\
\text { Juan Ohrner. }\end{array}$ \\
\hline
\end{tabular}

Fuente: Elaboración propia a partir de los protocolos de varios notarios del Archivo de Instrumentos Públicos de Jalisco. 
Como podemos observar, la red que construyó Teodoro Kunhardt a lo largo de su vida fue muy extensa y se tejía a través de los vínculos familiares; desde sus padres y hermanos, hasta sus hijos y yernos, pero además incluía una gran cantidad de empresarios, compañías e instituciones fuera de estos vínculos familiares. Su red de vínculos y negocios tocaba puntos muy importantes en los circuitos mercantiles internacionales y nacionales como Hamburgo, en Alemania; Valparaíso, en Chile; San Francisco, California y El Paso, Texas, en Estados Unidos, y en territorio mexicano, Guadalajara, Mazatlán, Tepic, Colima, León, Aguascalientes y Veracruz. Esta red fue continuada y aprovechada por sus hijos y yernos. Con la muerte de Kunhardt, los negocios se concentraron en su hijo Federico como representante de la compañía Teodoro Kunhardt y Sucesores. ${ }^{18}$

Francisco Martínez Negrete: dos generaciones, el padre y el bijo

En este caso hemos hecho hincapié en otro tipo de red; lo hacemos en gran medida para ejemplificar cómo estos dos individuos, que formaron empresas familiares $\mathrm{e}$ intervinieron en compañías por acciones como en los casos anteriores, ${ }^{19}$ desplegaron una red secundaria jurídico-económica no

\footnotetext{
${ }^{18}$ Valerio, "Teodoro", 2000, pp. 88-91.

${ }^{19}$ Para la reconstrucción histórica de las empresas creadas y en las que intervinieron Francisco Martínez Negrete Ortiz de Rosas y Francisco Martínez Negrete Alba véanse en Lizama, "Francisco", 2003, pp. 171187, y "Francisco Martínez", artículo entregado y aceptado para publicación, Universidad Autónoma del estado de Durango, 21 de abril de 2005.
}

menos importante que parece esencial en la seguridad y en el desarrollo e incremento de la fortuna familiar. Nos referimos al nombramiento de apoderados especiales y generales ${ }^{20}$ que los representaron a ellos, primero como individuos y, luego, como parte de las compañías mercantiles familiares que crearon y en las que participaron como accionistas. ${ }^{21}$

\section{Francisco Martinez Negrete Ortiz de Rosas}

Desde 1848, hasta principios de 1874, con la información notarial disponible hasta el momento, encontramos 32 apoderados especiales y generales, para que lo re-

${ }^{20}$ Los apoderados generales como su nombre lo indica, tenían por ley (Ley del Notariado, art. 85) una serie de atribuciones que les eran conferidas para que realizaran tareas en nombre de sus representados: seguir todos los trámites en los juicios de amparo por violación de las garantías individuales; recusar a los funcionarios y empleados judiciales y exigir responsabilidad a los que en ella incurrieren; prorrogar jurisdicción y arreglar el procedimiento convencional; transigir y convenir judicial y extrajudicialmente y comprometer todas las cuestiones que se dieran en contra; subrogar en términos y condiciones los créditos; presentar desistimiento; presentar instrumentos públicos y privados que se requirieran para el ejercicio del poder; celebrar transacciones y arreglos judiciales y extrajudiciales; someter los negocios que están a su cargo a la decisión de árbitros o de amigaloles componedores; competencia en los tribunales de la federación. Los apoderados especiales (poder especial) eran nombrados para realizar tareas específicas a nombre de sus representados.

${ }^{21}$ Aclaramos que todos los comerciantes y empresarios de la época tuvieron la misma práctica jurídicoeconómica en sus negocios y empresas, sin embargo, por ahora no nos es posible presentar el cuadro completo de este tipo de red por razones de espacio y de evolución de la investigación en curso. 
presentaran en Guadalajara, Zapotlán el Grande, Morelia, Guanajuato, San Juan de los Lagos, Colima, León, ciudad de México, Zamora e, incluso, Madrid. Tener operadores sobre los cuales se delegaron funciones económicas, legales y extralegales importantísimas significa que este comerciante tenía confianza en ellos, creía en su honorabilidad, sabía de su habilidad en el cumplimiento de las funciones encomendadas, es decir, a través del tiempo construyó un aparato en el cual apoyarse e hipotéticamente responde a un largo proceso de construcción de la confianza y la lealtad. Entre los apoderados hubo abogados de otras familias de la elite como los Camarena, por ejemplo, comerciantes, pero también fungieron como tales un hijo (José María) y algunos de sus yernos. ${ }^{22}$

La pregunta que queda en el aire es para qué y por qué tantos apoderados: 32 en 26 años. Tentativamente, a manera de hipótesis, se pueden aducir varias interpretaciones posibles. En el caso de los nueve avecindados en Guadalajara pudieron servir para representarlo cuando él estuvo fuera de la ciudad. El ejemplo gráfico de esto fue la compra, a través de un apoderado especial, de las casas que arrendaba al convento de San Agustín, en virtud de la Ley de Desamortización de los bienes de la Iglesia; también percibimos que esos representantes legales eran básicos e indispensables en todas las operaciones económicas que presentaran problemas, como, por ejemplo, en los pleitos por no pago de deudas de cualquier índole, lo que da pábulo para pensar que estas situaciones eran frecuentes; en las operaciones de com-

\footnotetext{
${ }^{22}$ Olveda hace una descripción parecida del comportamiento social y económico en "José", 1988, pp. $33-56$.
}

pras de bienes raíces para el finiquito de las mismas, y en pleitos de herencias. La existencia de apoderados especiales o generales nombrados en otras ciudades es explicable: ${ }^{23}$ cualquier comerciante y empresario de la época no podía prescindir de ellos, lo importante parece ser a quién designaba como tal.

Aunado a lo anterior y directamente relacionado con la construcción de la confianza, en este caso la que Francisco Martínez Negrete Ortiz de Rosas fue capaz de generar en los demás, están las diversas solicitudes que recibió para constituirse en fiador de algunos funcionarios públicos que en el desempeño de sus puestos requerían de un respaldo económico seguro. Los casos son el de Ignacio Vergara, quien se desempeñaría como tesorero contador de la Hacienda en Jalisco en 1845 y para esa tarea requería de un respaldo económico seguro por 6000 pesos. ${ }^{24}$ En 1856 , nue-

${ }^{23}$ Los protocolos notariales que registran estas acciones son los siguientes: AHIPJ, Juan Riestra, protocolos de: 14 de agosto de 1848 , fs. $130 \mathrm{v}-131 \mathrm{v} ; 17$ de marzo de 1852, fs. 82-82v; 27 de agosto de 1853 ; 7 de enero de 1854 , fs. 21-22; 31 de mayo de 1854 , fs. $288 \mathrm{v}-289 \mathrm{v} ; 10$ de julio de 1854 , fs. $378 \mathrm{v}-379$; 27 de febrero de 1855 , fs. $95-95 v ; 30$ de marzo de 1855 , fs. $147-148 ; 26$ de diciembre de 1857 , fs. $540 \mathrm{v}-541 \mathrm{v} ; 23$ de octubre de 1861 , fs. s/n; 2 de junio de 1862 , fs. $271 \mathrm{v}-273 \mathrm{v} ; 9$ de noviembre de 1865 , fs. $534 \mathrm{v}-535 ; 7$ de enero de 1868 , fs. $6 \mathrm{v}-7 \mathrm{v} ; 16$ de enero de 1868 , fs. $20-20 \mathrm{v} ; 17$ de agosto de 1868 , fs. $456-$ 456v; 12 de abril de 1871, fs. 230-230v. Mariano Hermoso, protocolo de 21 de noviembre de 1.8.18, fs. 130v-133v. Emeterio Robles Gil, protocolos de: 30 de junio de $1870 ; 25$ de julio de 1870, fj. 19; 23 de diciembre de 1870 , fs. $41-41 \mathrm{v} ; 27$ de diciembre de 1870 , fs. $42-42 \mathrm{v} ; 3$ de junio de 1871 , fs. $49 \mathrm{v}-50 \mathrm{v}, \mathrm{y}$ 17 de diciembre de 1872 , fs. 466-470.

${ }^{24}$ AhiPJ, Mariano Hermoso, 26 de agosto de 1845 , fs. $189 \mathrm{v}-190 \mathrm{v}$. 
vamente se constituyó en fiador, ahora de Miguel Hernández Rojas, síndico tesorero de la Universidad por la cantidad de 3000 pesos. Y, por último, realizó la misma función en el caso de Onofre Reyes por 4000 pesos, quien en 1861 fue tesorero de los fondos destinados a la Instrucción Pública: ${ }^{25}$

Francisco Martínez Negrete también fue nombrado representante legal de individuos de la sociedad de la región en la cual se movía y circulaba. En dos oportunidades vendió propiedades como apoderado del general José Cirilo Gómez, vecino de Lagos en un caso, y de Manuel Ortigosa residente en España, en el otro. ${ }^{26}$

En el transcurso de estos mismos años fue designado albacea de tres testamentarías, una de Juan Manuel Caballero, función que compartió con José Palomar; la segunda de Manuel Ruiz Gutiérrez, residente en España y heredero de Martín Gutiérrez, quien falleció en Guadalajara, y la tercera de Ramón Lasasola, ciudadano español. En estos dos últimos casos la función de vicecónsul de España fue decisiva en los respectivos nombramientos de albaceazgo de Francisco Martínez Negrete. ${ }^{27}$

Por último, su nombramiento como "arbitrador y amigable componedor" de un dictamen de partición de bienes en la disolución de la compañía mercantil de los hermanos Manuel y José Cortez, en 1862, es otra operación que muestra la confianza generada por este personaje.

${ }^{25}$ AHIPJ, Juan Riestra, 16 de febrero de 1854 , fs. $104 \mathrm{v}-105 \mathrm{v}$, y 26 de enero de 1861 , fs. $93-93 \mathrm{v}$.

${ }^{26}$ AHIPJ, Juan Riestra, 31 de agosto de 1847 , fs. $177 \mathrm{v}-182 ; 12$ de noviembre de 1850 , fs. 381-384.

${ }^{27}$ AHIPJ, Juan Riestra, 2 de diciembre de 1861 , fs. s. n., y 28 de octubre de 1865 . Véase también Olveda, Oligarquía, 1991, p. 269.

\section{Francisco Martínez Negrete Alba}

Después de la muerte de Francisco Martínez Negrete, en 1874 su hijo, de igual nombre, continúa en la actividad comercial y se desarrolla como empresario. Es lógico pensar que heredó la cartera de relaciones de su padre. Sin embargo, la época que le tocó vivir durante el porfiriato fue otra, caracterizada, como hemos señalado en otros trabajos, por una profundización de formas capitalistas, por la implementación de sociedades por acciones y anónimas que escaparon, en cierta medida, a la fuerte influencia estrictamente familiar, $y$, por ende, la red de relaciones de negocios tuvo que modificarse o ampliarse.

Es así que, entre 1874 y 1901 , etapa de vida activa como comerciante y empresario, podemos ver que hubo dos perfiles claramente diferenciados respecto de la red de apoyo jurídico-económico que debió tejer: una como individuo/gerente de su empresa familiar, y otra como parte de un colectivo empresarial. En ambos casos el nombramiento de apoderados generales y especiales muestra los vínculos espaciales, es decir, hasta dónde se extendieron los negocios en el ámbito regional y con quienes tejió la red.

Como individuo/gerente de la empresa familiar que formó primero con su cuñado -Justo Fernández del Valle- y, luego de finiquitada ésta, otra formada con sus hijos, Francisco Martínez Negrete Alba tuvo operadores jurídicos que lo apoyaron en sus negocios y que debieron de ser de su confianza. El cuadro 3 muestra la lista de sus operadores.

Un balance preliminar de esta serie de contratos realizados ante notario por Francisco Martínez Negrete Alba, que especifican los nombres de los individuos y las 


\section{Cuadro 3. Operadores de Francisco Martínez Negrete Alba}

\begin{tabular}{|c|c|c|c|}
\hline$A \tilde{n} o$ & Nombre del operador & $\begin{array}{l}\text { Lugar de la } \\
\text { representación }\end{array}$ & Objetivo de la representación \\
\hline 1874 & Antonio de la Peña & Mascota & $\begin{array}{l}\text { Juicio en Mascota para recuperar } \\
\text { bienes en contra de Pedro Ramos. }\end{array}$ \\
\hline 1878 & Rafaèl López & Guadalajara & Atender sus negocios en Guadalajara. \\
\hline 1881 & J. Refugio Guinchard & Aguascalientes & $\begin{array}{l}\text { Hacer las cobranzas a sus deudores y } \\
\text { seguir los juicios correspondientes } \\
\text { en Aguascalientes. }\end{array}$ \\
\hline 1887 & Avelino Herrera & La Barca & $\begin{array}{l}\text { Hacer las cobranzas a sus deudores en } \\
\text { La Barca. }\end{array}$ \\
\hline 1888 & José Trinidad Verea & Guadalajara & $\begin{array}{l}\text { Juicio contra Lebre Bassiere y Cía., } \\
\text { por derechos de servidumbre en una } \\
\text { casa de su propiedad en Guadalajara. }\end{array}$ \\
\hline 1891 & José Trinidad Verea & Guadalajara & $\begin{array}{l}\text { Poder general para que lo represente } \\
\text { en cualquier pleito. }\end{array}$ \\
\hline 1891 & Miguel Alba & San Juan de los Lagos & $\begin{array}{l}\text { Recobrar una casa de su propiedad en } \\
\text { San Juan de los Lagos. }\end{array}$ \\
\hline 1893 & $\begin{array}{l}\text { Francisco Martínez } \\
\text { Negrete (hijo) }\end{array}$ & Guadalajara & $\begin{array}{l}\text { Para que lo represente en todos } \\
\text { sus negocios. }\end{array}$ \\
\hline 1895 & Ignacio de Anda & San Juan de los Lagos & $\begin{array}{l}\text { En lugar de Miguel de Alba, para } \\
\text { continuar con el reclamo de la } \\
\text { entrega de la casa en San Juan } \\
\text { de los Lagos. }\end{array}$ \\
\hline 1905 & $\begin{array}{l}\text { Andrés Bermejillo } \\
\text { Martínez Negrete }\end{array}$ & Ciudad de México & $\begin{array}{l}\text { Juicio por los bienes de la } \\
\text { testamentaría de su hermana } \\
\text { Francisca Martínez Negrete. }\end{array}$ \\
\hline
\end{tabular}

Fuente: Elaboraciôn propia a partir de la información del Archivo de Instrumentos Públicos de Jalisco, Varios Notarios: AHIPJ, Juan Riestra, 9 de octubre de 1874, fs. 839-840; Francisco González Palomar, 20 de marzo de 1878, f. 6, y 7 de abril de 1905, fs. 13-14; Enrique Ahumada, 20 de junio de 1881, f. 3; José María Alfaro, 6 de diciembre de 1887, f. 40; 20 de marzo de 1888, f. 52, y 27 de octubre de 1888, f. 72v; Francisco García Sancho, 4 de agosto de 1890, fs. 2-3; José Verea, 2 de octubre de 1891, fs. 99-101; 3 de octubre de - 1893, fs. 1.15-117 y 23 de septiembre de 1895, fs., 69-71, y Salvador España, 23 de octubre de 1891, f. 78.

acciones para las cuales los faculta, mediante poderes generales y especiales, nos muestra que en su mayoría eran comerciantes y abogados, sin olvidar que también las encomendó a familiares directos (hijo y sobrino).
Las tareas que debían desempeñar cran básicas para el buen funcionamiento de sus negocios. Sin ese personal de apoyo no era posible realizar tantas operaciones económicas en un ámbito geográfico tan amplio. 


\section{SECUENCIA}

\section{Rieve Ouders,}

De Oorlog tegen de rebellen is begonnen. D. ITexikanen vervolgen ombarmikartig alle sreemdelingen. $I_{k}$ blijf hier zolang mogelijk om de boerderij te verdedigen. $\mathcal{O}_{e i l}$ hoop beotaat er echter niet meer.

\section{นw Žon ชిillem.}

$3-5$ 
A manera de hipótesis se puede plantear que la elección de estos individuos, probables puntales jurídicos, no pudo ser azarosa ni meramente técnico-profesional, sino que la hizo con base en la confianza que ellos le despertaban y aseguraban. Esto es muy claro cuando le da dichas atribuciones a su hijo en el momento quizá más importante de su vida como comerciante y empresario. Ahora bien, nos queda claro que, si bien es una red secundaria, no por ello es menos importante en el devenir de los negocios.

Otro rasgo observable en la construcción de esta red es que persiste la tendencia iniciada y desarrollada por su padre y otros empresarios y comerciantes; ésta es que sus negocios tuvieron como centro Guadalajara, pero se extendieron a un ámbito regional más amplio, aunque más reducido que el de su padre.

Siguiendo con esta misma variable, es decir, la red jurídica que comerciantes y empresarios crearon para el mejor desarrollo de sus negocios y empresas, se puede descubrir que Francisco Martínez Negrete Alba también desempeñó esta función, que puede ser evidencia de la confianza que en él tuvieron para encomendársela, lo cual se muestra en el cuadro 4.

Haciendo un balance preliminar de estos cuatro casos en que Francisco Martínez Negrete Alba actúa como representante legal para desempeñar funciones específicas se observa, en primer lugar, que el lazo sanguíneo hizo posible que perviviera el lazo económico-jurídico: el hijo heredó una función del padre; en efecto, aunque en el cuadro no es posible mencionarlo, el documento respectivo sí dice que Francisco padre fue albacea de las mismas personas y que Francisco hijo mantuvo la representación de dicha familia residente en
España. En segundo término, que las encomiendas que recibió de empresarios ricos evidencian los vínculos de parentesco $y$ de negocios que tuvo con ellos. Y ambos a la vez pueden ser leídos como productos de la confianza que pudo existir entre ellos.

Hay una tercera posibilidad para observar los vínculos económico-jurídicos: utilizar la misma variable donde aparece Francisco Martínez Negrete Alba dentro de un colectivo empresarial formado por el agrupamiento de varias compañías, que tienen un representante en común (véase cuadro 5).

En el cuadro 5, en el contrato que tenemos a la vista, la acción encomendada a Ramón Alcaraz perfila varios aspectos que deben realzarse. Primero, en el banco que se formó persiste la presencia de lazos de parentesco, pues encontramos como accionistas a los hermanos Fernández de Valle que, como hemos dicho anteriormente, eran parientes políticos de Francisco Martínez Negrete Alba; segundo, se anuncia un relevo generacional en estas dos familias, pues aparecen los hijos de estos comerciantes y empresarios como firmantes del acuerdo en que se nombra a Alcaraz como representante legal; tercero, la presencia de individuos y de compañías de origen mexicano, español y francés, y cuarto, como mera hipótesis, una colaboración de capital interregional. ${ }^{28}$ Restaría agregar que Francisco Martínez Negrete sale del grupo empresarial financiero en 1901 cuando se produce la quiebra total de sus negocios y, lo que es aún más dramático, es excluido de la red empresarial, social y de negocios. Esto último lo dice él

${ }^{28}$ Sobre la creación e historia del Banco de Jalisco véase Valerio, Empresarios, 2002, pp. 129-134. 
Cuadro 4. Poderes que recibió Francisco Martínez Negrete y Alba de otras personas

\begin{tabular}{|c|c|c|c|}
\hline$A \tilde{n} o$ & Otorgante & residencia & Objetivos \\
\hline 1882 & Juan José Paz & España & $\begin{array}{l}\text { Apoderado y encargado de varias fincas } \\
\text { en Guadalajara. }\end{array}$ \\
\hline 383 & Guillermo Barron & Ciudad de México & $\begin{array}{l}\text { Compraventa de acciones por } 60000 \\
\text { pesos de las fábricas texriles. }\end{array}$ \\
\hline 90 & $\begin{array}{l}\text { José López Portillo y } \\
\text { Rojas y Margarita Weber }\end{array}$ & Guadalajara & $\begin{array}{l}\text { Realizar contratos de arrendamiento y } \\
\text { cobrar rentas de dos casas en Tepic } \\
\text { y de la mitad del rancho Puerta de } \\
\text { Escobar. }\end{array}$ \\
\hline 92 & José María Bermejillo & Ciudad de México & $\begin{array}{l}\text { Formalizar con el Ayuntamiento de } \\
\text { Guadalajara el contrato para } \\
\text { establecer el alumbrado eléctrico } \\
\text { en Guadalajara. }\end{array}$ \\
\hline
\end{tabular}

Fuente: Elaboración propia a partir de la información del Archivo de Instrumentos Públicos de Jalisco, Varios Notarios. AHJPJ, Heraclio García Diego, 11 de diciembre de 1882, f. 117, y 29 de agosto de 188.3, fs. 49-49v; Genaro B. Ramírez, 26 de diciembre de 1890, fs. 506-507, y 30 de enero de 1891, f. 508; Ramón E. Ruiz, 14 de julio de 1892 , fs. $37-38$.

mismo en algunas de las cartas que escribió entre 1901 y 1902 a diferentes integrantes de su familia directa y algunos de sus amigos. ${ }^{29}$

\section{COMPAÑÍAS MERCANTILES, OTRO TIPO DE NUDO EN LA RED}

Durante el siglo xIX en México las compañías y/o sociedades establecidas con objetivos económicos eran asociaciones de in-

29 Archivo de la Biblioteca Pública de Jalisco, Libro Copiador de Correspondencia de Francisco Martínez Negrete Alba, 1901-1902. Este volumen contiene 500 cartas que dirigió a familiares y amigos entre esos años, documento transcrito y en proceso de estudio y análisis. dividuos independientes unos de otros, que decidían en determinado momento asociarse para constituir una empresa económica dedicada a uno o a varios giros mercantiles, industriales, agrícolas o financieros. Si comenzamos analizando las compañías mercantiles más simples, nos daremos cuenta de la compleja red de vínculos y relaciones que está detrás de cada pequeña empresa mercantil.

Por ejemplo, formalmente las compañías que administraban los almacenes comerciales de telas, vestidos y artículos de consumo importados y del país, conocidos como Las Fábricas de Francia, El Nuevo Mundo, La Ciudad de México, El Nuevo París y la Ciudad de Londres, entre otros, eran empresas integradas por tres o cuatro socios. Pero con una particularidad 


\section{Cuadro 5. Poderes otorgados por Francisco Martínez Negrete Alba como parte de un colectivo empresarial}

\begin{tabular}{|c|c|c|c|}
\hline Año & $\begin{array}{l}\text { Nombre del } \\
\text { representante }\end{array}$ & Otorgantes & Objetivo \\
\hline 1874 & Hornedo y Cía. & $\begin{array}{l}\text { Álvarez Araujo y Cía., Octling } \\
\text { y Cía., Francisco Martínez } \\
\text { Negrete, Fernández del Valle } \\
\text { y Cía., Fernández Somellera } \\
\text { Hnos., Fernando Peña y Hnos., } \\
\text { Teodoro Kunhardt, Ángel Puga. }\end{array}$ & $\begin{array}{l}\text { Representarlos en un juicio sobre } \\
\text { el pago de } 1.5 \% \text { por la exportación } \\
\text { de moneda a Veracruz, en la ciudad } \\
\text { de Aguascalientes. }\end{array}$ \\
\hline 1879 & Salvador Gómez & $\begin{array}{l}\text { Francisco Martínez Negrete y } \\
\text { Cía., Fernández Somellera Hnos., } \\
\text { Fernández del Valle Hnos., } \\
\text { Sandoval Franco y Cía. }\end{array}$ & Representación legal. \\
\hline 1887 & Vicente Lork & $\begin{array}{l}\text { Justo Fernández del Valle, } \\
\text { Francisco Martínez Negrete } \\
\text { y Rafael López. }\end{array}$ & $\begin{array}{l}\text { Poder general para que los } \\
\text { represente en la Cía. Minera La Luz. }\end{array}$ \\
\hline 1887 & José Felipe Díaz & $\begin{array}{l}\text { Manuel Corcuera y Luna, } \\
\text { Rafael López y Francisco } \\
\text { Martínez Alba. }\end{array}$ & $\begin{array}{l}\text { Poder especial para cobrar adeudos } \\
\text { de Cesareo Monroy, comerciante } \\
\text { de Cocula. }\end{array}$ \\
\hline 1891 & Miguel Alba & $\begin{array}{l}\text { Francisco Martínez Negrete } \\
\text { Alba, Manuel y Justo Fernández } \\
\text { del Valle, Juan Somellera, } \\
\text { Manuel L. Corcuera, Modesto } \\
\text { y Gonzalo Ancira, Diego e } \\
\text { Ignacio Moreno, Gas y Cogordan, } \\
\text { y Fortoul y Chapuy y Cía. }\end{array}$ & $\begin{array}{l}\text { Poder general para que los } \\
\text { represente en San Juan de los lizgos } \\
\text { ante el gobierno federal y local y } \\
\text { en juicios particulares. }\end{array}$ \\
\hline 1897 & Ramón Alcaraz & $\begin{array}{l}\text { Fernández del Valle Hnos., } \\
\text { Fortoul Chapuy y Cía., Morenos } \\
\text { Hnos., L. Gas y Cía., José L. } \\
\text { García y Manuel L. Corcuera, } \\
\text { Francisco Martínez Negrete. }\end{array}$ & $\begin{array}{l}\text { Poder especial y todas las facultades } \\
\text { para que los represente ante el } \\
\text { Ministerio de Hacienda a fin de } \\
\text { obtener la concesión de un banco } \\
\text { de emisión en Guadalajara con } \\
\text { sucursales en Colima y Tepic. }\end{array}$ \\
\hline
\end{tabular}

Fuente: Elaboración propia a partir de la información del Archivo de Instrumentos Públicos de Jalisco. Virrios Notarios: AHIPJ, Juan Riestra, 5 de octubre de 1874, fs. 829-830; Diego Baza, 18 de febrero de 1879, f. 6v; Heraclio García Diego, 2 de abril de 1887, fs. 115-118; Francisco González Palomar, 27 de octubre de 1887, f. 93v.; José Verea, 29 de enero de 1891, fs. 76-78v, y 27 de diciembre de 1897, fs. 134-140. 
muy importante, todos ellos eran de origen francés, en gran parte provenientes de la misma región de Francia: de Barcelonnette. Estos franceses fueron los protagonistas de uno de los más importantes flujos migratorios que tuvieron como destino al continente americano, y en especial a México, durante el siglo XIX. Siguieron un patrón muy socorrido por los grupos humanos que tienen la necesidad de salir de su pueblo natal en busca de oportunidades y de riqueza: la migración en cadena.

Se establecieron en las ciudades más importantes de México, entre ellas Guadalajara, y fundaron los almacenes comerciales más prominentes de telas, vestidos, sombreros, artículos de lujo, corsetería y bonetería. Con ello introducían el gusto por el consumo suntuario y la moda venida de París. Aunque cada uno de estos inmigrantes franceses había dejado atrás su pueblo y su nación, nunca rompieron totalmente sus vínculos con su comunidad natal; tendieron lazos constantes entre la ciudad a la que llegaron a residir y el pueblo del cual provenían, incluso ni los lazos familiares se interrumpieron del todo, ya que los dueños de los negocios establecidos en México trajeron a sus parientes, amigos o conocidos de su pueblo o región y los recibieron en sus almacenes como socios o empleados.

Desde sus inicios estas compañías fueron un nudo que vinculaba a dos comunidades humanas muy distantes geográficamente y eran los intermediarios que vinculaban los circuitos mercantiles en el mundo con los mercados de consumo local en México, especialmente en Guadalajara y su región. Estas compañías generalmente tenían relaciones muy estrechas con sus socios y agentes radicados en Francia, espe- cialmente en París, quienes les enviaban los productos que se expendían en las casas comerciales de Guadalajara.

Las Fábricas de Francia, que comenzaron sus actividades comerciales hacia 1876 , fueron fundadas por Desiderio Bonnafoux, León Fortoul, Adrián Berlie y José Chapuy. La compañía se reorganizaba cada tres o cinco años retirando algunos socios y admitiendo otros, entre los que podemos contar a Luis Fortoul, Augusto Bec, Juan Roffino, Lorenzo Bernardi, Luis Lebre, Pedro Langier, Teófilo Lebre, Amado y Eduardo Gandoulf y Federico Fordean, durante el último cuarto del siglo XIX y las dos primeras décadas del xx. León Fortoul y Augusto Bec fueron los socios que radicaban permanentemente en París, enviaban mercancías al almacén de Guadalajara y enviaban y recibían capitales de uno y otro lado del Atlántico. ${ }^{30}$

Las Fábricas de Francia, además del almacén de ropa y de novedades, tenían un taller para la confección de ropa y una fábrica de sombreros en donde empleaban a los inmigrantes franceses que llegaban a Guadalajara desde su región natal, con contratos previamente establecidos entre los dueños del negocio y los empleados.

Casi de la misma manera operaban otros almacenes comerciales, propiedad de franceses en Guadalajara, como La Ciudad de México que se estableció en 1880 , y sus socios principales fueron Eugenio Cogordan, Adrián Berlie, Luis Gas, Félix Cogordan, Antonio Gas, Eliseo Reynaud, Eduardo Gueymard, Eugenio Cuzin y Benjamín Feissier. En este caso, Luis Gas era quien residía permanentemente en Europa. Para atender sus intereses y nego-

${ }^{30}$ Valerio, Empresarios, 2002, pp. 43-46. 
cios en la ciudad de México, la compañía había dado poder a los señores J. B. Ebrad y Cía. Sucesores, para que los representaran en dicha ciudad, con lo que se muestran los vínculos de estas compañías con otras del mismo tipo y nacionalidad radicadas en la capital del país hacia fines del porfiriato. $^{31}$

Otro ejemplo de estas negociaciones comerciales fue la La Ciudad de París, fundada en la década de 1880 . Entre sus socios se encontraban José Bellon, Martín Agarreca, Luciano Burle, Teófilo Fortoul y Ernesto Javelly. Los señores Agarreca y Bellón continuamente hacían viajes a Europa, quienes enviaban a su negociación, situada en Guadalajara, telas producidas en Lyon, hilos y otros artículos desde Francia, Suiza e Inglaterra. El Nuevo París realizaba operaciones de mayoreo en la costa del Pacífico, desde Colima hasta Cananea, Sonora. Conectada con esta casa comercial se encontraba la fábrica de sombreros denominada El Sombrero Colorado, fundada en febrero de 1878 por León Honnorat y los hermanos Teófilo y Fernando Fortoul. ${ }^{32}$

Cada uno de los socios de estas casas comerciales o compañías tenía su propia red de vínculos con otros empresarios y compañías. El caso de Teófilo Fortoul nos puede dar un ejemplo de ello: originario de Jausiers, Bajos Alpes, Francia, nació el 30 de julio de 1829 y fue hijo de Francisco Fortoul y Felicitas Cogordan. En 1849, a los 19 años de edad, Teófilo salió de Jauisers rumbo a México, llegó a Guadalajara a mediados de la década de 1850 y se casó en la ciudad de Durango con

\footnotetext{
31 Ibid., pp. 46-50.

${ }^{32}$ Ibid., pp. 54-55.
}

Aleja Navarrete. Fue hermano de Fernando Fortoul, otro empresario francés que llegó a Guadalajara. Se asoció con los hermanos Pablo y Antonio Leautaud en la negociación denominada La Feria de San Juan en 1867. Luego fundó con León Honnorat y su hermano Fernando la fábrica de El Sombrero Colorado. También fue socio fundador del almacén denominado La Ciudad de París junto con José Bellon y Martín Agarreca. A su muerte, ocurrida en Guadalajara el 12 de abril de 1899 , dejó sus bienes a su esposa, quien vivía en Guadalajara, y a sus parientes radicados en Jausiers, entre ellos sus hermanos Fanny y Fernando, a sus sobrinos Teófilo Silve, María y Sidonia Roffino, Fernanda Fortoul, Luis Allemand, Fernando y Victoria Maigre, y a sus primas Margarita Maigre y Juana Fortoul..$^{33}$ En sus inventarios se encontraron créditos a su favor a cargo de varias negociaciones: la Casa E. Maynier Suc., de la ciudad de México le debía 35000 pesos; la Bellón Agarreca y Cía. le debía la misma cantidad; la negociación L. Gas y Cía. le adeudaba 13 000; Eligia Ramírez de la Parra otros 10 000; en tanto que Juan Gómez le debía 3 000; tenía acciones en el Banco de Jalisco por 10000. Su fortuna total fue valuada en 233990 pesos. ${ }^{34}$ Su red era muy extensa geográficamente, pues tocaba puntos como Jausiers, Francia, la ciudad de México y la ciudad de Guadalajara.

\footnotetext{
${ }^{33}$ AHIPJ, José López Portillo y Rojas, t. 2, 10 de marzo de 1896.

34 AHIPJ, Alberto Méndez, Libro de Documentos, 1900, y tomo del 17 de abril de 1899 .
} 
SOCIEDADES POR ACCIONES Y ASOCIACIONES DE COMPAÑÍAS, EL NUDO MÁS COMPLEJO DE LA RED

Las sociedades por acciones reunían a un número mayor de empresarios individuales y a compañías más pequeñas, con el fin de concentrar un volumen de capital más grande. ${ }^{35}$ Claramente se observa que el nudo que formaban estas sociedades era más denso y enrevesado que las anteriores y que su funcionamiento implicaba una organización más compleja a través de la designación de un consejo directivo y administrativo, así como su organización por departamentos y sucursales. Si observamos en detalle a cada una de estas empresas, podremos ver que varios de los socios participaban con sus capitales en dos o más compañías, lo cual significa que, aunque eran empresas independientes unas de otras, sus vínculos eran muy estrechos en términos de propiedad y dirección. Además de que en muchas de estas empresas los proveedores y clientes eran los mismos socios que participaban en la empresa.

El cuadro 6 nos muestra a diez empresas formadas durante el porfiriato en Guadalajara, las cuales tienen vínculos y nexos a través de sus socios que a la vez son accionistas, directivos, familiares, clientes, proveedores y prestamistas de dichas empresas, y que se relacionan con almacenes y casas comerciales e industriales que operan en Guadalajara y que son de estos mismos socios. Asimismo, se puede observar que los vínculos que tejen los empresarios

${ }^{35}$ Podríamos definir esta red como un grupo de compañías que trabajó en conjunto para comercializar sus productos, adquirir insumos, dotarse de servicios comunes, organizarse para la producción especializándose y complementarse entre sí. que tienen acciones en más de una empresa se ramifican a todos los socios, por lo que el cuadro puede ampliarse a más empresas y podremos ver todo el tejido empresarial si es posible, y tendremos la información suficiente.

\section{CONCLUSIONES}

Definitivamente, las redes se tejen con propósitos distintos. La red familiar que se estructura a partir de los vínculos de sangre, de los afectos primarios, es, sin duda, uno de los tejidos más fuertes y seguros, por donde fluyen los capitales, el crédito, la confianza, las influencias, el prestigio, la autoridad y el honor. El estudio de redes de parentesco permite observar la forma en que se integraron las redes familiares que derivaron en redes de comerciantes y de empresarios y los cambios que éstas registraron a lo largo de un siglo. Esto probablemente permitió a "individuos obtener capital, socios leales, información rápida y fiable, y agentes fieles distribuidos por muy distintas áreas geográficas". ${ }^{36}$ Situación ciertamente no menor en el ejercicio del comercio y en el funcionamiento de las empresas.

En el caso de los individuos y grupos analizados en este ensayo se corroboran estos aspectos de forma detallada y precisa. Ninguno.de los empresarios estudiados, ya fueran de nacionalidad mexicana, española, alemana o francesa, prescindió de esta red consanguínea y de parentesco, la cual trascendía en algunos casos las fronteras regionales.

Sin embargo, ello no fue un obstáculo para que individualmente o por grupo fa-

${ }^{36}$ La cita es de Fernández, Rostro, 1997, p. xx. 
Cuadro 6. Sociedades por acciones establecidas en Guadalajara

Nombre de la compañia

Banco Nacional de México en Guadalajara (1)

Compañía Minera La Asturiana (2)

Compañía Industrial de Jalisco (3)

Compañía Minera de San Pedro Analco (4)

Cía. Minera de la Luz y San Juan Nepomuceno (5)

Banco de Jalisco (6)

Compañía Industrial de Guadalajara (7)

Compañía Anónima Ferrocarrilera (8)

Compañía de Fomento y Bienes Raíces (9)

Compañía Jalisciense de Construcciones (10)

$\begin{array}{ccc}\begin{array}{c}\text { Año de } \\ \text { formación }\end{array} & \begin{array}{c}\text { Capital social } \\ \text { (pesos) }\end{array} & \begin{array}{c}\text { Núm. } \\ \text { de socios }\end{array} \\ 1884 & 300000 & \\ 1887 & 24000 & 12 \\ 1889 & 1000000 & 7 \\ 1890 & 200000 & 11 \\ 1891 & 250000 & 10 \\ 1898 & 500000 & 10 \\ 1899 & 2000000 & 5 \\ 1880 & 105000 & 12 \\ 1910 & 6000000 & 14 \\ 1898 & 160000 & 4\end{array}$

Socios y empresas de las que son accionistas

Socio

Banco de Jalisco

L. Gas y Cía.

A. Brun y Cía.

Eugenio Cuzin

Aurelio González Hermosillo

Augusto Brun

Abraham Gallardo

José Pacheco

Enrique Feissier

Antonio Brun

Pedro Signoret

Juan Nigg

Eduardo Caire

Víctor Signoret

Faustino Somellera

Francisca Martínez Negrete Alba

Juan A. Aguirre y Cía.

Fernández del Valle Hermanos

Antonio Garagarza

Trinidad Verea

Martín Gavica

Francisco Martínez Negrete Alba X X

Somellera Hermanos

Fernández Somellera Hermanos

\section{Compañia}

$\begin{array}{llllllllll}1 & 2 & 3 & 4 & 5 & 6 & 7 & 8 & 9 & 10\end{array}$

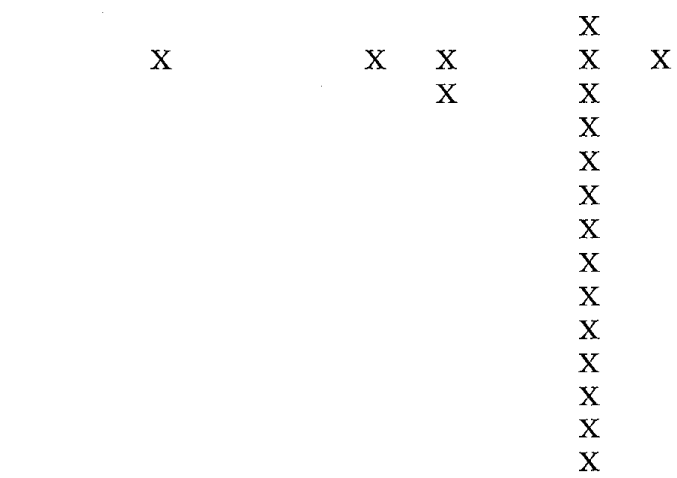

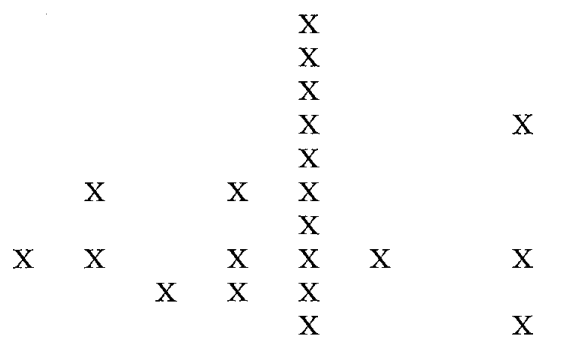

Redes empresariales en la región de Guadalajara 
Socio

Manuel Fernández del Valle

Justo Fernández del Valle

Francisco Fernández del Valle

Antonio Álvarez del Castillo

Lino Martínez

Ramón Gómez

Jesús Castillo

Sociedad Anónima La Armonía

Francisco Vallarta

Salvador Gómez

Fernández del Valle Hermanos

Alfredo Lonergan

Patricio García Cortina

Ramón Miravete

Nicolás Remus e Hijas

Gabriel Castaños

Juan Camba

Moreno Hermanos

Manuel L. Corcuera

Ancira y Hermano

Fortoul y Chapuy

E. Lebre y Cía.

Bellón Agarreca y Cía.

Juan Somellera

Luciano Gómez

Alfonso Heyman

Ramón Alcaraz

José L. García

Jesús Camarena

Agustín L. Gómez

Ignacio Arzápalo

Froilán Michel

Pablo Navarrete

Francisco Ma. Ortiz

Rafael Sánchez

Néstor Arce

Teodoro Kunhardt

Ernesto Fuchs

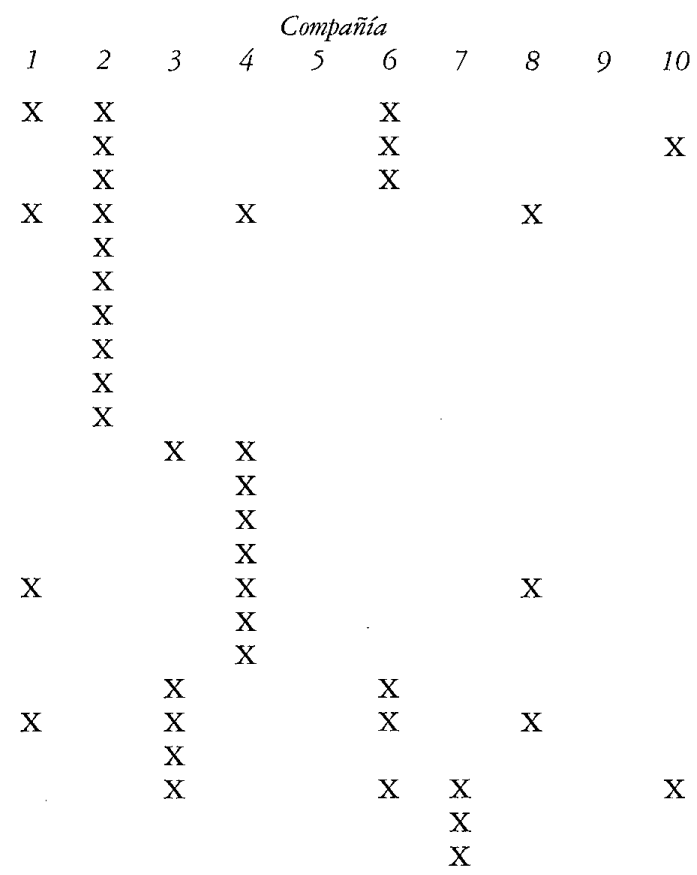

$\mathrm{X}$

$\mathrm{X}$

$\mathrm{X}$

$\mathrm{x}$

$\mathrm{X}$

$\mathrm{X}$

$\mathrm{X}$

$\mathrm{X}$

$\mathrm{X}$

$\mathrm{X}$

$\mathrm{X}$

$\mathrm{X}$

$\mathrm{X}$

Fuente: Elaboración propia a partir de Valerio, Empresarios, 2002. Las compañías se tratan con detalle en dicha obra. 
miliar se tejieran otros hilos que apuntaban hacia fuera de la red familiar. Los empresarios de la región de Guadalajara conformaron redes muy complejas que incluían a diversos individuos y compañías. Ello se observa a partir del análisis de la conformación de empresas, las relaciones internas entre los socios, y la participación en diversas compañías como capitalistas, socios, directores y administradores. Aunque era considerable el número de empresas y empresarios que había en la región del occidente de México, se observa claramente una estructura piramidal en donde una pequeña minoría de grandes empresarios eran los que poseían, controlaban, dirigían y administraban las empresas más grandes e importantes de la región, y las relaciones entre este grupo eran muy estrechas, pues se basaban en las redes de parentesco, amistad, paisanaje o nacionalidad, compadrazgo y clientelismo tanto económico como político. Este grupo de empresarios privilegiados constituía una elite económica que controlaba la vida económica y social de la región.

Distintos tipos de redes se entrelazan en el tejido social y económico, de tal manera que podemos observar cuáles de ellos son los que están en la base y cuáles se configuran como tejidos secundarios. En el símil de la red podríamos decir que hay hilos que dibujan figuras caprichosas sobre la tela, o dibujos con patrones bien establecidos. Estas figuras pueden ser constituidas por las redes del crédito o de los operadores comerciales o financieros que utilizan los empresarios para allegarse recursos o para atender los asuntos que se presentan a distancia. Las redes del crédito o de los representantes y operadores puede seguir los hilos del parentesco o del tejido empresarial de los socios de mane- ra muy estrecha, pero no se queda ahí, también incluye a intermediarios financieros, comisionistas, comerciantes, abogados o profesionistas en general, que muchas veces no están directamente relacionados con el representado por lazos de parentesco o por vínculos empresariales, sino por cuestiones formales, es decir, simples contratos o poderes notariales.

Las redes empresariales en el occidente de México podrían tener como centro la ciudad de Guadalajara como el nudo más abigarrado del tejido social y económico, ahí confluían todos los hilos, y ahí se enredaban en una apretada madeja. Pero también de ahí salían muchos otros hilos que vinculaban a ese mercado urbano con las otras poblaciones dentro y fuera de la región, llegando a distintas partes del país y del extranjero, formando parte de otras redes en el ámbito nacional e internacional, de tal manera que se torna difícil encontrar la punta de la hebra en este enmarañado flujo de productos, capitales, personas, influencias e información.

\section{FuENTES CONSULTADAS}

\section{Archivos}

AHIPJ. Archivo Histórico y de Instrumentos Públicos de Jalisco.

Archivo de la Biblioteca Pública de Jalisco.

\section{Bibliografía}

-Bertrand, Michel, "De la familia a la red de sociabilidad", Revista Mexicana de Sociología, vol. 6i, núm. 2, abril-junio de 1999, México.

-Fernández Pérez, Paloma, El rostro familiar de la metrópoli. Redes de parentesco y lazos mercantiles en Cádiz, 1700-1812, Siglo XXI, Madrid, 1997. 
-Lizama Silva, Gladys, "Francisco Martínez Negrete: un comerciante y empresario de la elite tapatía, 1824-1874", en Águeda Jiménez P., Elites y poder. México y España, siglos XVI al XX, Universidad de Guadalajara, Guadalajara, 2003.

-López, Juan, Guadalajara y sus mandatarios de 1532 a1986, UNED/Gobierno de Jalisco, Guadalajara, 1987.

-Ludlow, Leonor, "La formación del Banco Nacional de México: aspectos institucionales y sociales" en Leonor Ludlow y Carlos Marichal (coords.), La banca en México, 1820-1920, Instituto Mora/El Colegio de Michoacán/ColmeX/ UNAM, México, 1998.

-Martínez Reding, Fernando, Los tapatíos, un modo de vivir, Ayuntamiento de Guadalajara, Guadalajara, 1987.

-Olveda, Jaime, "José Palomar: prototipo del empresario pre-burgués”, Relaciones, El Colegio de Michoacán, vol. Ix, núm. 36, 1988.

- La oligarquia de Guadalajara, Conaculta, México, 1991.

-Pérez Verdía, Luis, Historia particular del estado de Jalisco, Universidad de Guadalajara, Guadalajara, 1989, t. 11 .
-Santoscoy, Alberto, Obras completas, UNED/ Gobierno de Jalisco, Guadalajara, 1986, t. II.

- Valerio Ulloa, Sergio, "Empresarios capitalistas y terratenientes en Jalisco durante el siglo XIX. El caso de Nicolás Remus" en María Eugenia Romero Ibarra y Pablo Serrano Álvarez (coords.), Regiones y expansión capitalista en México durante el siglo XIX, UNAM /Universidad de Colima, México, 1998.

—, "Capitalismo y oligarquía en Jalisco, 1876-1910", tesis doctoral, Colmix, México, 1999.

—_, "Teodoro Kunhardt, un empresario alemán en Guadalajara. Fortunas y empresas a travếs de los protocolos notariales" en Rafael Torres Sánchez (coord.), Fuentes para el estudio de la bistoria regional. Aportaciones en torno al seminario de Historia y Vida Cotidiana, Universidad de Guadalajara, Guadalajara, 2000.

- Empresarios extranjeros en Guadalajara durante el porfiriato, Universidad de Guadalajara, Guadalajara, 2002. 